\title{
Variability of Peripheral Pulse Wave Velocity in Patients With Diabetes Mellitus Type 2 During Orthostatic Challenge
}

\author{
Jana SVAČINOVÁ ${ }^{1}$, Jana HRUŠKOVÁ ${ }^{1,2}$, Juraj JAKUBÍK ${ }^{1,2}$, Ksenia BUDINSKAYA ${ }^{1}$, \\ Simona HIDEGOVÁ ${ }^{2}$, Martin Fabšík ${ }^{1,3}$, Helena SIEGLOVÁ ${ }^{1}$, Zuzana KAŠČÁKOVÁ ${ }^{1,3}$, Jan \\ NOVÁK ${ }^{3}$, Zuzana NOVÁKOVÁ ${ }^{1}$
}

${ }^{1}$ Department of Physiology, Faculty of Medicine, Masaryk University, Brno, Czech Republic, ${ }^{2}$ International Clinical Research Center, St. Anne's University Hospital Brno, Brno, Czech Republic, ${ }^{3}$ Second Department of Internal medicine, St. Anne's Faculty Hospital and Faculty of Medicine, Masaryk University, Brno, Czech Republic

Received March 30, 2020

Accepted October 6, 2020

\begin{abstract}
Summary
Diabetes mellitus 2 (DM2) is the seventh cause of death worldwide. One of the reasons is late diagnosis of vascular damage. Pulse wave velocity (PWV) has become an independent marker of arterial stiffness and cardiovascular risk. Moreover, the previous studies have shown the importance of beat-to-beat PWV measurement due to its variability among the heart cycle. However, variability of PWV (PWVV) of the whole body hasn't been examined yet. We have studied a group of DM II and heathy volunteers, to investigate the beat-to-beat mean PWV (PWVm) and PWVV in the different body positions. PWV of left lower and upper extremities were measured in DM2 (7 m/8 f, age $68 \pm 10$ years, BP $158 / 90 \pm 19 / 9 \mathrm{~mm} \mathrm{Hg}$ ) and healthy controls $(5 \mathrm{~m} / 6 \mathrm{f}$, age $23 \pm 2$ years, BP $117 / 76 \pm 9 / 5 \mathrm{~mm} \mathrm{Hg}$ ). Volunteers were lying in the resting position and of head-up-tilt in $45^{\circ}$ (HUT) for 6 min. PWV $v$ was evaluated as a mean power spectrum in the frequency bands LF and HF (0.04-0.15 Hz, 0.15-0.5 Hz). Resting PWVm of upper extremity was higher in DM2. HUT increased lower extremity PWVm only in DM2. Extremities PWVm ratio was significantly lower in DM2 during HUT compared to controls. LF and HF PWVv had the same response to HUT. Resting PWVV was higher in DM2. Lower extremity PWVv increased during HUT in both groups. PWVm and PWVV in DM2 differed between extremities and were significantly influenced by postural changes due to hydrostatic pressure. Increased resting PWVm and PWVV in DM2 is a marker of increased arterial stiffness.
\end{abstract}

\section{Key words}

Pulse wave velocity • Variability • Diabetes mellitus • Arterial stiffness • Orthostasis

\section{Corresponding author}

J. Svačinová, Department of Physiology, Faculty of Medicine, Masaryk University, Brno, Czech Republic Kamenice 735/5, 62500 Brno, Czech Republic. E-mail: svacinova@med.muni.cz

\section{Introduction}

Pulse wave velocity (PWV) is a gold standard for estimation for the arterial stiffness: lower arterial stiffness leads to the higher PWV. Aortic PWV is an independent predictor of future cardiovascular events and all-cause mortality (Laurent et al. 2001, Boutouyrie et al. 2002, Vlachopoulos et al. 2010, Lee et al. 2018). Arterial stiffness evaluated in the form of carotid-femoral or heart-femoral PWV is the most preferred index however both parameters includes mainly central (aortic) PWV (Lee et al. 2018). Not only aortic PWV, but also peripheral PWV, such as brachial-ankle or femoral-ankle PWV, can be used as a parameter of vascular damage (Lee et al. 2018, McEniery et al. 2005, Meyer et al. 2016).

PWV depends on the vessel structure and condition. Physiologically, peripheral (muscular) arteries contain smooth muscle layer controlled by the sympathetic nervous system as well as vasoactive substances. The changes of the nervous system affect the compliance of arterial wall (Scott et al. 2001 Polónia et al. 2003). Aortic compliance is higher than in peripheral arteries compliance due to structural and 
functional differences. Therefore, PWV in peripheral arteries could provide different and more complex information than aortic PWV (Meyer et al. 2016).

Other factors influencing PWV are endothelial function, blood pressure, blood volume, arterial distension, and structural changes. PWV is a marker of vascular aging and endothelial function (Lee et al. 2018, McEniery et al. 2006, McEniery et al. 2005). Blood pressure and blood volume are parameters strongly influencing PWV: increased blood pressure and filling of artery lead to arterial distension and as a consequence in a decreasing of compliance (Boutouyrie et al. 2002, Moudr et al. 2014). The previous studies has shown that Aortic stiffness clearly increases with structural changes caused by age (McEniery et al. 2005, Wen et al. 2015). In summary, PWV is influenced by many factors associated with vascular function.

Standard measurement of PWV is evaluated as a mean value from several cardiac cycles, mostly supine position. However, most pathological changes can appear only after some provocation or by stress testing such as exercise, position change, or application of vasoactive drugs (Polónia et al. 2003, Langer et al. 2018, Matejkova et al. 2014, Gaddum et al. 2014, Obata et al. 2016). Conversely, spontaneous variability of PWV without any provocation during steady-state conditions could contain information about the vascular regulatory mechanism. This applies especially to the muscular arteries with variable tone controlled by the autonomic nervous system (ANS) (Joannides et al. 1995, Boutouyrie et al. 1994). Unlike well-studied variability of beat-to-beat heart rate (HRV) and blood pressure (BPV) used as a marker of the ANS activity the variability of PWV (PWVv) is not fully studied. (Rajendra et al. 2006, Honzikova et al. 1975, Parati et al. 1995). We assume, that PWV variability expressed by spectral analysis contains similar spectral components like in HRV and BPV because of the interaction between heart rate, blood pressure, and PWV (Svacinova et al. 2015).

Diabetes mellitus type 2 as a chronic progressive vascular disease (DM2) affects PWV by several ways. Endothelial dysfunction and structural arterial changes are caused by long-lasting hyperglycemia and hyperinsulinemia. Diabetic autonomic neuropathy impairs sympatho-vagal balance toward sympathetic predominance over the muscular arteries (Cruickshank et al. 2002). DM2 is also accompanied by hypertension, atherosclerotic process, and associated complications.

We have studied a group of mid age DM II and young heathy volunteers, to investigate the differences in mean PWV (PWVm) and PWVv. Both groups were measured at the tilting table.

To provoke the shift in the variability of PWV influenced by age and DM2.

The aim of the preliminary study was to analyze the effect of the orthostatic challenge to the lower and upper extremities PWV and its variability in DM2 and health control volunteers.

\section{Methods}

\section{Subjects}

Studied group contained 15 patients with DM2 ( 7 male $/ 8$ female, age $68 \pm 10$ years, blood pressure $158 / 90 \pm 19 / 9 \mathrm{~mm} \mathrm{Hg}$ ). DM2 volunteers without other serious comorbidities was an only inclusion criterion. Control group consisted of 11 healthy young volunteers ( 5 male $/ 6$ female, age $23 \pm 2$ years, blood pressure $117 / 76 \pm 9 / 5 \mathrm{~mm} \mathrm{Hg}$ ). The main exclusion criteria for healthy control group were acute infection, cardiovascular diseases, obesity, diabetes mellitus, and ingestion of substances affecting the cardiovascular system at least $24 \mathrm{~h}$ before measurement.

\section{Pulse wave velocity recording}

Multichannel bioimpedance monitor (MBM, developed by the Institute of Scientific Instruments of The Czech Academy of Sciences) is the continuous beat to beat measurement of the elasticity of arteries (Plesinger et al. 2014, Matejkova et al. 2015, Vondra et al. 2016, Langer et al. 2018, Soukup et al. 2019). The method is based on the bioimpedance principle. Basically, transient blood flow increase caused by pulse wave passing between two electrodes induces impedance change. PWV can be evaluated from distances between electrodes and durations of pulse wave passage. Simultaneously electrocardiogram (ECG) was recorded. This method is able to evaluate beat-to-beat PWV in various body parts separately (Fig. 1). In this study, sequences of PWVs were recorded in the left arm and left leg.

\section{Protocol}

The participants were lying in the supine position resting $6 \mathrm{~min}$ before performing the measurement. Then the PWVs were measured for the $6 \mathrm{~min}$ (phase of supine position). After measurement at the supine position participant was tilted at the neurological tilting table at the degree of $45^{\circ}$ for the $6 \mathrm{~min}$ (phase HUT). Current electrodes were placed at the neck, hands, 
and legs. Bioimpedance electrodes were placed at the chest, hands, and legs for obtaining limb PWV at the two different hemodynamical conditions.

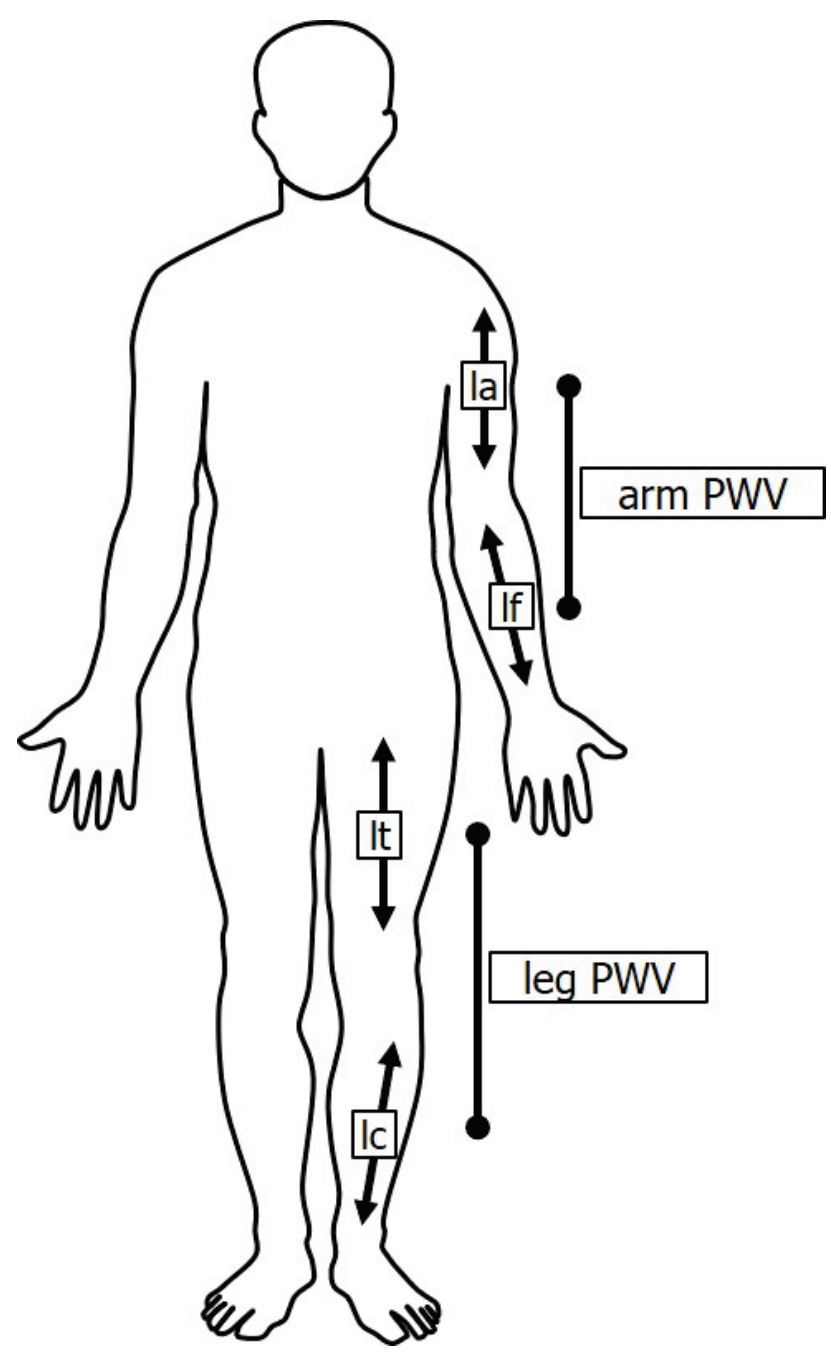

Fig. 1. Multichannel bioimpedance method: arrows indicate the position of electrodes (a total of 8 electrodes, 4 for each extremity), where Ia stands for arm bioimpedance lead, If - forearm bioimpedance lead, It - thigh bioimpedance lead and Ic - calf bioimpedance lead. Passage of the pulse wave between the electrodes determining the lead causes impedance change. PWV is calculated from distance between physical midpoints of the leads Ia and If, respectively It and Ic and transit time of the pulse wave.

\section{Data analysis}

Mean PWVs were evaluated from sequence $p w v$ containing 300 consecutive beat-to-beat PWV samples. Mean arm and leg PWV (PWVm) were evaluated for each subject and phase. The ratio of the arm/leg PWVm was calculated for each subject and phase of measurement. Variability of the beat-to-beat PWV $(\mathrm{PWV})$ was evaluated as a mean spectral power of $p w v$ in the low-frequency band (LF, 0.04-0.15 Hz) and highfrequency band ( $\mathrm{HF}, 0.15-0.5 \mathrm{~Hz}$ ). Kolmogorov-Smirnov test proved non-Gaussian distribution of data; therefore, non-parametric tests were used. Mann-Whitney test was used for the evaluation of the difference between DM2 patients and controls. Wilcoxon pair test was used for evaluation of the difference between phases and extremities.

\section{Results}

Example of beat-to-beat PWV for one DM2 patient and control is shown in Figure 2. Supine PWVm was higher in DM2 than in controls (Fig. 3). HUT led to increase of leg PWV in DM2. PWVm ratio arm/leg significantly decreased during HUT in DM2 compared to controls, therefore HUT PWVm ratio arm/leg was lower in DM2 in comparison to controls.

PWVV is shown in Figure 4. HUT led to a significant increase in $\mathrm{PWVv}$ in controls regardless to the frequency band or extremity. DM2 showed an increase of PWVV only in the leg. However, variability in DM2 was higher in the leg than in arm during HUT in both frequency bands. DM2 had higher PWVv than controls in the following variables and situations: armsupine-LF, arm-supine-HF, leg-supine-HF, arm-hut-HF.

\section{Discussion}

Innovative method of bioimpedance PWV measurement used in this study has several advantages. It can detect beat-to-beat PWV in various parts of the body. Therefore not only mean PWV but also changes of PWV in response to the orthostatic challenge in particular arteries could be analysed in this study (Plesinger et al. 2014, Plesinger et al. 2014, Vondra et al. 2016). This study was focused on changes of PWV and its variability in the group of healthy participants and DM2 patients, to evaluate the variables reflecting the changes in the vessels. Participants from the healthy control were selected from a younger age to exclude the other vascular pathologies.

\section{Changes of mean PWV}

Supine PWV was higher in DM2 than in controls. HUT led to the highlighting of the difference between DM2 and controls in the leg. DM2 had a stronger response to the HUT, especially in leg, which was expressed by arm/leg ratio. 


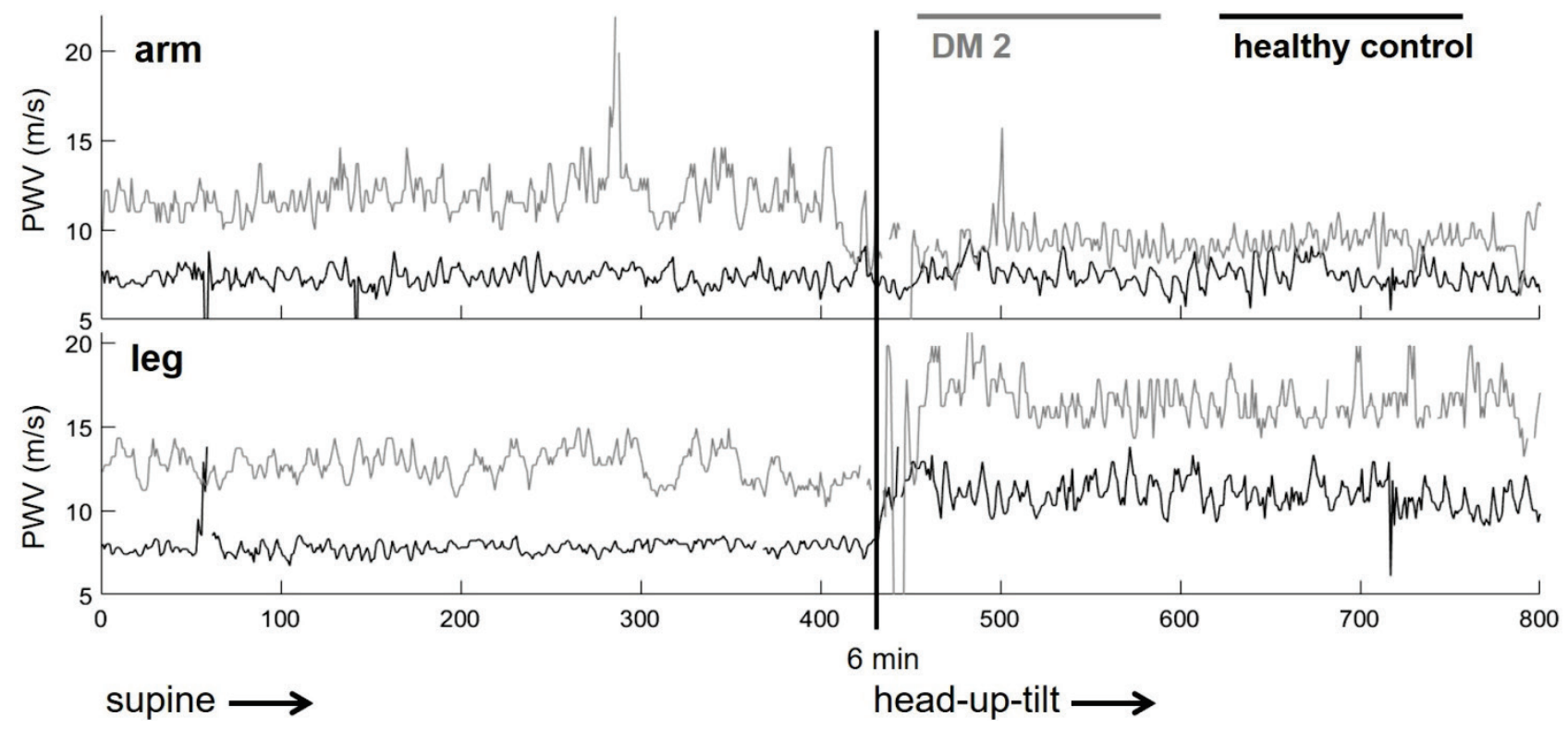

Fig. 2. An example of beat-to-beat PWV in leg and arm in patient with diabetes mellitus 2 (DM2) and healthy control. Tilt-table test was made in $45^{\circ}$.
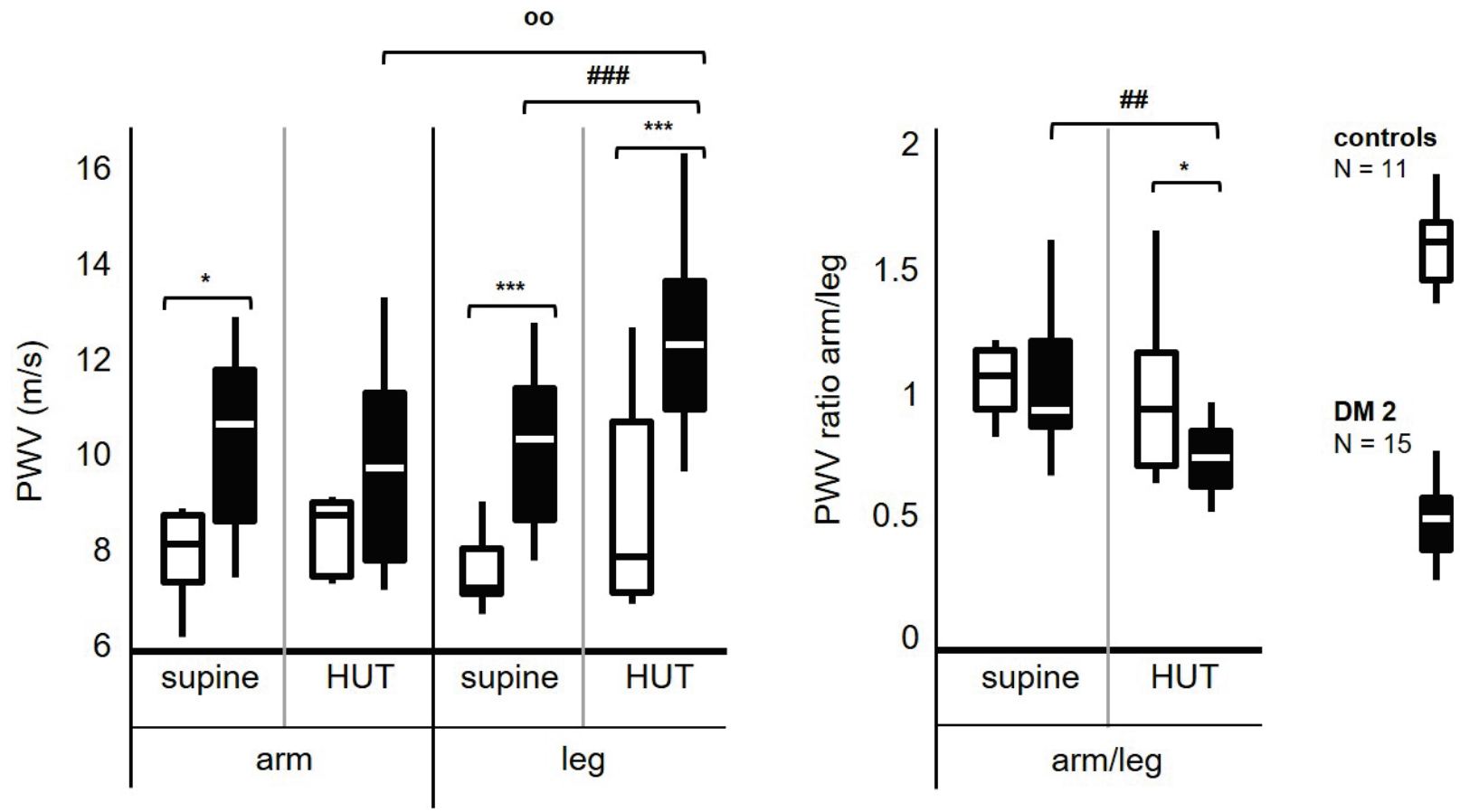

Fig. 3. Distribution of PWV and ratio PWV arm/leg. Subjects: 11 healthy controls: ( 5 male/ 6 female) and 15 patients with diabetes mellitus 2 (DM2, 7 male/8 female). HUT: head-up-tilt in 45․ DM2 vs. controls (Mann-Whitney test): $* p<0.05 ; * * p<0.01 ; * * * p<0.001$. Supine vs. HUT (Wilcoxon test): ${ }^{\#} p<0.05 ;{ }^{\# \#} p<0.01 ;{ }^{\# \#} p<0.001$. PWV arm vs. PWV leg (Wilcoxon test): ${ }^{\circ} p<0.05 ;{ }^{\circ} p<0.01$.

Blood pressure is a very important determinant of PWV regardless of the structural and functional arterial wall changes (Wang et al. 2014). Both, diabetes mellitus 2 and higher age, increase PWV by increased blood pressure (Kim et al. 2006, Wen et al. 2015). Increase of the leg PWV during the orthostatic challenge was clearly caused by blood redistribution and increased hydrostatic pressure and volume in lower limbs (Plesinger et al. 2014, Matejkova et al. 2015). Arterial compliance determining PWV is not constant. Compliance non-linearly depends on arterial distension caused by increased transmural pressure and/or on filling of the artery (Moudr et al. 2014, Cymberknop et al. 2019, Weltman et al. 1964). 


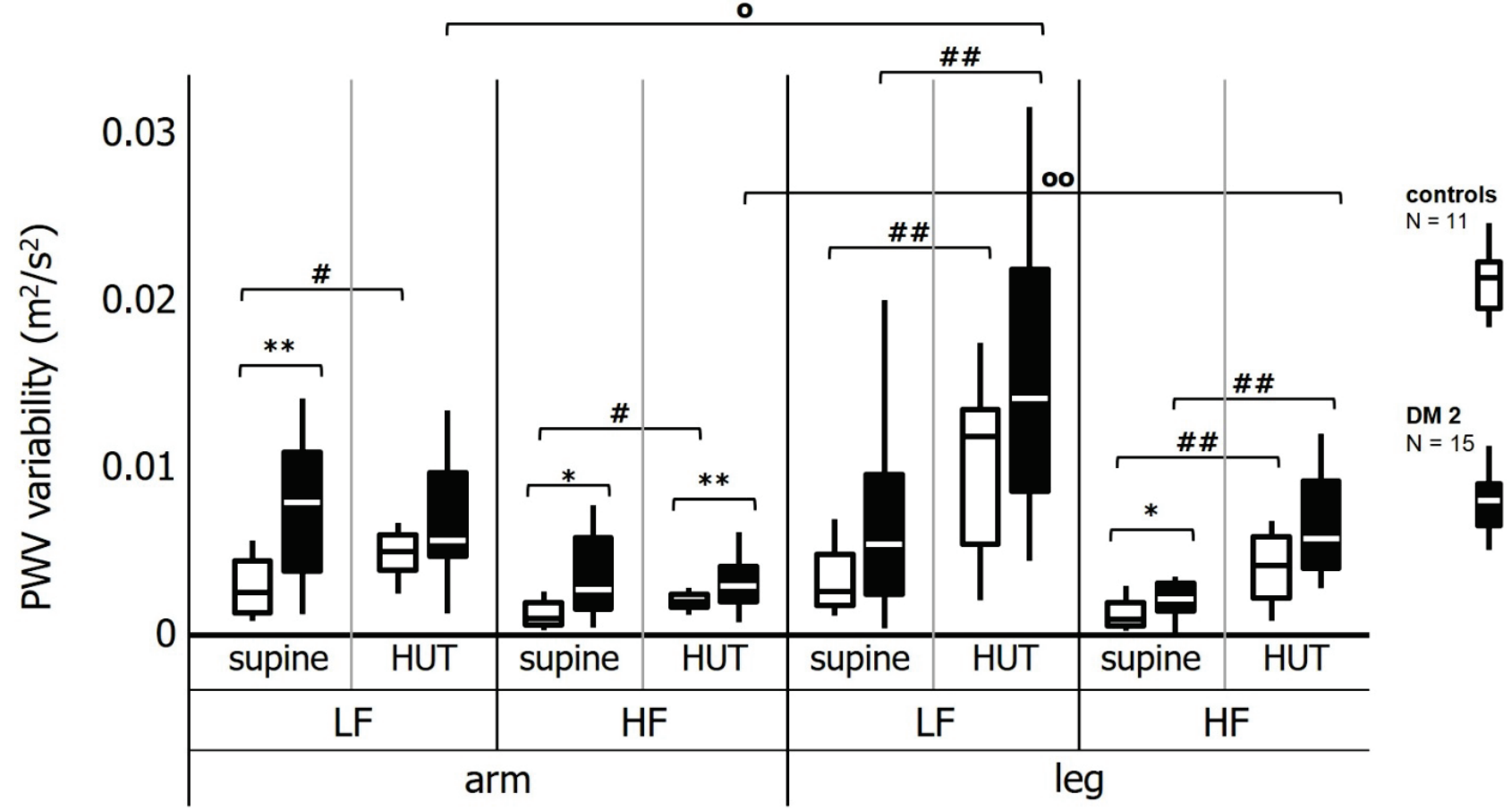

Fig. 4. Distribution of PWV variability evaluated as a spectral power in low frequency (LF: $0.04-0.15 \mathrm{~Hz})$ and high frequency band (HF: $0.15-0.5 \mathrm{~Hz}$ ). Subjects: 11 healthy controls: ( 5 male/ 6 female) and 15 patients with diabetes mellitus 2 (DM2, 7 male/8 female). HUT: head-up-tilt in $45^{\circ}$. DM2 vs. controls (Mann-Whitney test): $* p<0.05 ; * * p<0.01$. Supine vs. head-up-tilt $45^{\circ}$ (Wilcoxon test): ${ }^{*} p<0.05$; $\#$ \# $\mathrm{p}<0.01$; PWV arm vs. PWV leg (Wilcoxon test): ${ }^{\circ} \mathrm{p}<0.05 ;{ }^{\circ 0} \mathrm{p}<0.01$.

We supposed that DM2 patients had negatively influenced endothelial function and led to the structural changes of the arterial wall, both increasing arterial stiffness (McEniery et al. 2006). Higher blood pressure or remodeled arterial wall could be a possible reason for higher resting PWV in DM2. Increased arterial stiffness in diabetes mellitus 2 was proved in elastic (aortic) as well as in peripheral (muscular) arteries of diabetics (Zhang et al. 2011).

DM2 showed a stronger increase of leg PWV compared to controls. It could be given by changed autonomic control over the vessels and dysregulation of blood redistribution, diabetic neuropathy and angiopathy (Chorepsima et al. 2017). Moreover, vascular response (vasoconstriction/increasing of the vascular tone) to the orthostatic challenge in lower limbs is provided by the local mechanism such as veno-arteriolar response (VAR) (Brothers et al 2009). In case of vascular impairment in DM2 the primary target is microcirculation and as the result affection of VAR (Strain and Paldánius 2018, Namgoong et al. 2019). The orthostatic challenge can be a useful provocation maneuver to better detect pathology in vascular response, but correction of PWV on blood pressure in the measured artery is strongly recommended.

\section{Changes of $P W V$ variability}

Changes of PWV variability were more complex. DM2 generally had higher resting PWVv than controls. HUT led to increase of PWVv in the legs of both groups, while variability in arm increased only in controls. During HUT, DM2 had higher PWVv in the leg than in the arm.

Studies analyzing PWV variability were usually focused on day-to-day or longer intervals between measurements mainly to evaluate the reproducibility of PWV (Tripkovic et al. 2014, Kallem et al. 2013, Bode et al. 2012). Beat-to-beat PWV variability is practically unexplored, but some studies described variability in differences between peripherally measured pulse intervals and RR-intervals from ECG, which are associated with the similar source of variability as a PWV (Hayano et al. 2005, Schäfer and Vagedes 2013, Del Paso et al. 2010).

Wang et al. (2014) proved that transit time, as a component of a PWV (PWV = distance / transit time) together with heart rate can be used to calculate blood pressure. Therefore transit time can be taken as a surrogate for BPV.

BPV and HRV expressed by spectral analysis contains well known spectral components in LF and HF band, therefore we expected at least some similarities in power spectra of PWV (Honzikova et al. 1975, Parati 
et al. 1995). We observed higher PWVV in LF, but the response of LF and HF to HUT did not differ.

Higher variability in LF was probably connected with low-frequency BPV called Mayer waves. It is a question if the variability in PWV was given mostly by BPV, or PWV variability and BPV were of the same origin, i.e. slow changes of the vascular tone. Orthostatic challenge leads to the Mayer waves formation and increases of BPV in LF (Julien 2006, Myers et al. 2001). The increase is associated with the activation of the sympathetic nervous system. Therefore, the connection with the Mayer waves can be supported by finding, that LF PWVV markedly increased during HUT. LF BPV increase during hut is presented also in diabetes mellitus 2 without neuropathy. Diabetic neuropathy lead to lower LF BPV during orthostatic challenge (Casali et al. 2018, Wang et al. 2011).

Higher PWV variability in DM2 compared to controls could be explained by other hypotheses. Firstly, it was given by increased arterial stiffness and worsened ability of arteries to dump fast BP changes compared to controls. It is possible, that impaired autonomic control over the arteries in DM2 caused higher changes of vascular tone (Verrotti et al. 2014). And finally, generally higher mean PWV provided larger space for PWVv.

\section{Conclusions}

Multichannel bioimpedance PWV is a beat-to-beat noninvasive measurement of the PWV with the possible simultaneous examination legs and arms. Mean PWV in lower and upper limbs responded differently to the HUT because of higher hydrostatic pressure in lower limbs. The resting PWV was higher in DM2, but HUT led to highlighting the difference in lower limbs. PWV ratio arm/leg seems to be interesting variable for clinical implementation and evaluation of arterial stiffness in people at higher cardiovascular risk. BPV is probable source for PWVv. Resting PWVv was higher in DM2 as well. Although HUT led to the increase of PWVv especially in lower limbs, the difference between healthy controls and DM2 during HUT was not significant. LF PWVV variability during HUT could be associated with Mayer waves in BPV. PWVv is a complex parameter and there are many possible reasons for higher mean PWV and its variability in DM2, such as diabetic neuropathy and changed sympathetic response to the HUT, vascular remodelation, endothelial dysfunction or other. PWVv probably contains complex information about all these factors, which requires further investigation.

\section{Limitations}

The influence of aging, diabetes mellitus and hypertension on PWV and its variability cannot be separated. Therefore, the major limitation of the study is in the selection of the control group, when we have investigated the healthy group of young adults. As a control group, normotensive age-matched non-diabetics should be used. However, the aim was to prove, how impedance is able to detect these clear changes in arterial stiffness. For a better understanding of PWV changes, correlation with diabetic parameters such as duration of diabetes, glucose tolerance, fasting plasma glucose, glycated hemoglobin, etc. should be made (Chorepsima et al. 2017, Zhang et al. 2011).

\section{Conflict of Interest}

There is no conflict of interest.

\section{Acknowledgements}

Supported by funds from the Faculty of Medicine MU to junior researcher (J. Svačinová, ROZV/28/LF18/2020). Supported by: MUNI/A/1307/2019, MUNI/A/1403/2019, LQ1605 (MEYS CR, NPU II). Some of results have been published in: Svačinová J, Hidegová S, Sieglová $\mathrm{H}$, et al. $A$ different response of the upper and lower limb beat-tobeat pulse wave velocity to the orthostatic challenge. Masaryk University Press; 2019. Accessed July 29, 2020. https://www.muni.cz/vyzkum/publikace/1584738.

\section{References}

BODE AS, LEERMAKERS J, KROON JW, BRANDS P, PLANKEN RN, TORDOIR JHM: Determination of brachial artery stiffness prior to vascular access creation: reproducibility of pulse wave velocity assessment. Nephrol Dial Transplant 27: 2370-2376, 2012. https://doi.org/10.1093/ndt/gfr687

BOUTOUYRIE P, LACOLLEY P, GIRERD X, BECK L, SAFAR M, LAURENT S: Sympathetic activation decreases medium-sized arterial compliance in humans. Am J Physiol Heart Circ Physiol 267: H1368-H1376, 1994. https://doi.org/10.1152/ajpheart.1994.267.4.H1368 
BOUTOUYRIE P, TROPEANO AI, ASMAR R, GAUTIER I, BENETOS A, LACOLLEY P, LAURENT S: Aortic stiffness is an independent predictor of primary coronary events in hypertensive patients: a longitudinal study. Hypertension 39: 10-15, 2002. https://doi.org/10.1161/hy0102.099031

BROTHERS RM, WINGO JE, HUBING KA, DEL COSO J, CRANDALL CG: Effect of whole body heat stress on peripheral vasoconstriction during leg dependency. J Appl Physiol 107: 1704-1709, 2009. https://doi.org/10.1152/japplphysiol.00711.2009

CASALI KR, SCHAAN BD, MONTANO N, MASSIERER D, NETO FMF, TELÓ GH, LEDUR PS, REINHEIMER M, SBRUZZI G, GUS M: Correlation between very short and short-term blood pressure variability in diabetichypertensive and healthy subjects. Arq Bras Cardiol 110: 157-165, 2018. https://doi.org/10.5935/abc.20180020

CHOREPSIMA S, ELEFTHERIADOU I, TENTOLOURIS A, MOYSSAKIS I, PROTOGEROU A, KOKKINOS A, SFIKAKIS PP, TENTOLOURIS N: Pulse wave velocity and cardiac autonomic function in type 2 diabetes mellitus. BMC Endocr Disord 17: 27, 2017. https://doi.org/10.1186/s12902-017-0178-2

CRUICKSHANK K, RISTE L, ANDERSON SG, WRIGHT JS, DUNN G, GOSLING RG: Aortic pulse-wave velocity and its relationship to mortality in diabetes and glucose intolerance: an integrated index of vascular function? Circulation 106: 2085-2090, 2002. https://doi.org/10.1161/01.CIR.0000033824.02722.F7

CYMBERKNOP LJ, GABALDÓN CASTILLO F, ARMENTANO RL: Beat to beat modulation of arterial pulse wave velocity induced by vascular smooth muscle tone. In: 2019 41st Annual International Conference of the IEEE Engineering in Medicine and Biology Society (EMBC), pp 5030-5033, 2019. https://doi.org/10.1109/EMBC.2019.8856538

DEL PASO GAR, GONZALEZ MI, HERNANDEZ JA: Comparison of baroreceptor cardiac reflex sensitivity estimates from inter-systolic and ECG R-R intervals. Psychophysiology 47: 1102-1108, 2010.

GADDUM NR, SCHAEFFTER T, BÜHRER M, RUTTEN M, SMITH L, CHOWIENCZYK PJ, BEERBAUM PBJ: Beat-to-beat variation in pulse wave velocity during breathing maneuvers. Magn Reson Med 72: 202-210, 2014. https://doi.org/10.1002/mrm. 24890

HAYANO J, BARROS AK, KAMIYA A, OHTE N, YASUMA F: Assessment of pulse rate variability by the method of pulse frequency demodulation. Biomed Eng Online 4: 62, 2005. https://doi.org/10.1186/1475-925X-4-62

HONZIKOVA N, PENAZ J, FISER B: Spectral analysis of spontaneous fluctuations of some cardiovascular variables. Physiol Bohemoslov 24: 441-442, 1975.

POLÓNIA J, BARBOSA L, SILVA JA, MALDONADO J: Different influences on central and peripheral pulse pressure, aortic wave reflections and pulse wave velocity of three different types of antihypertensive drugs: Rev Port Cardiol 22: 1485-1492, 2003.

JOANNIDES R, RICHARD V, MOORE N, GODIN M, THUILLEZ C: Influence of sympathetic tone on mechanical properties of muscular arteries in humans. Am J Physiol Heart Circ Physiol 268: H794-H801, 1995. https://doi.org/10.1152/ajpheart.1995.268.2.H794

JULIEN C: The enigma of Mayer waves: Facts and models. Cardiovasc Res 70: 12-21, 2006. https://doi.org/10.1016/j.cardiores.2005.11.008

KALLEM RR, MEYERS KEC, SAWINSKI DL, TOWNSEND RR: Variation and variability in carotid-femoral pulse wave velocity. Artery Res 7: 230-233, 2013. https://doi.org/10.1016/j.artres.2013.04.001

KIM EJ, PARK CG, PARK JS, SUH SY, CHOI CU, KIM JW, KIM SH, LIM HE, RHA SW, SEO HS, OH DJ: Relationship between blood pressure parameters and pulse wave velocity in normotensive and hypertensive subjects: invasive study. J Hum Hypertens 21: 141-148, 2007. https://doi.org/10.1038/sj.jhh.1002120

KINLAY S, CREAGER MA, FUKUMOTO M, HIKITA H, FANG JC, SELWYN AP, GANZ P: Endothelium-derived nitric oxide regulates arterial elasticity in human arteries in vivo. Hypertension 38: 1049-1053, 2001. https://doi.org/10.1161/hy1101.095329

LANGER P, JURAK P, VONDRA V, HALAMEK J, MESTANIK M, TONHAJZEROVA I, VISCOR I, SOUKUP L, MATEJKOVA M, ZAVODNA E, LEINVEBER P: Respiratory-induced hemodynamic changes measured by whole-body multichannel impedance plethysmography. Physiol Res 67: 571-581, 2018. https://doi.org/10.33549/physiolres.933778 
LAURENT S, BOUTOUYRIE P, ASMAR R, GAUTIER I, LALOUX B, GUIZE L, DUCIMETIERE P, BENETOS A: Aortic stiffness is an independent predictor of all-cause and cardiovascular mortality in hypertensive patients. Hypertension 37: 1236-1241, 2001. https://doi.org/10.1161/01.HYP.37.5.1236

LEE SW, HAN SH, YOO TH, CHUNG W, PARK SK, CHAE DW, AHN C, OH K-H: Relationship between brachialankle and heart-femoral pulse wave velocities and the rapid decline of kidney function. Sci Rep 8: 821, 2018. https://doi.org/10.1038/s41598-018-19334-w

MATEJKOVA M, VONDRA V, HALAMEK J, SOUKUP L, PLESINGER F, VISCOR I, JURAK P: Measurement of pulse wave velocity during Valsalva and Mueller maneuvers by whole body impedance monitor. Comp Cardiol 2014: 1117-1120, 2014.

MATEJKOVA M, VONDRA V, SOUKUP L, PLESINGER F, VISCOR I, HALAMEK J, JURAK P: Changes of pulse wave velocity in the lower limbs in hypertensive patients. In: 2015 Computing in Cardiology Conference (CinC) vol 42, ed A Murray, (New York: Institute of Electrical and Electronics Engineers), pp 257-260, 2015. https://doi.org/10.1109/CIC.2015.7408635

MCENIERY CM, YASMIN, HALL IR, QASEM A, WILKINSON IB, COCKCROFT JR, INVESTIGATORS ACCT: Normal vascular aging: Differential effects on wave reflection and aortic pulse wave velocity: The Anglo-Cardiff Collaborative Trial (ACCT). J Am Coll Cardiol 46: 1753-1760, 2005. https://doi.org/10.1016/j.jacc.2005.07.037

MCENIERY CM, WALLACE S, MACKENZIE IS, MCDONNELL B, YASMIN N, NEWBY DE, COCKCROFT JR, WILKINSON IB: Endothelial function is associated with pulse pressure, pulse wave velocity, and augmentation index in healthy humans. Hypertension 48: 602-608, 2006. https://doi.org/10.1161/01.HYP.0000239206.64270.5f

MEYER ML, TANAKA H, PALTA P, PATEL MD, CAMPLAIN R, COUPER D, CHENG S, AL QUNAIBET A, POON AK, HEISS G: Repeatability of central and peripheral pulse wave velocity measures: the atherosclerosis risk in communities (ARIC) study. Am J Hypertens 29: 470-475, 2016. https://doi.org/10.1093/ajh/hpv127

MOUDR J, SVAČINOVÁ J, ZÁVODNÁ E, HONZÍKOVÁ N: The vibration plethysmographic method of arterial compliance analysis in dependence on transmural pressure. Physiol Res 63 (Suppl 4): S489-S495, 2014. https://doi.org/10.33549/physiolres.932929

MYERS CW, COHEN MA, ECKBERG DL, TAYLOR JA: A model for the genesis of arterial pressure Mayer waves from heart rate and sympathetic activity. Auton Neurosci Basic Clin 91: 62-75, 2001. https://doi.org/10.1016/S1566-0702(01)00289-2

NAMGOONG S, YANG J-P, HAN S-K, LEE Y-N, DHONG ES: Influence of peripheral neuropathy and microangiopathy on skin hydration in the feet of patients with diabetes mellitus. Wounds 31: 173-178, 2019.

OBATA Y, MIZOGAMI M, SINGH S, NYHAN D, BERKOWITZ DE, STEPPAN J, BARODKA V: The effects of hemodynamic changes on pulse wave velocity in cardiothoracic surgical patients. BioMed Res Int 2016: e9640457, 2016. https://doi.org/10.1155/2016/9640457

PARATI G, SAUL JP, DIRIENZO M, MANCIA G: Spectral-analysis of blood-pressure and heart-rate-variability in evaluating cardiovascular regulation - a critical-appraisal. Hypertension 25: 1276-1286, 1995. https://doi.org/10.1161/01.HYP.25.6.1276

PLESINGER F, MATEJKOVA M, HALAMEK J, JURAK P, VISCOR I, VONDRA V: Influence of tilt load on pulse wave velocity in the lower limbs. In: 2014 8th Conference of the European Study Group on Cardiovascular Oscillations (ESGCO), Trento, 2014, pp. 77-78. https://doi.org/10.1109/ESGCO.2014.6847527

RAJENDRA AU, PAUL JK, KANNATHAL N, LIM CM, SURI JS: Heart rate variability: a review. Med Biol Eng Comput 44: 1031-1051, 2006. https://doi.org/10.1007/s11517-006-0119-0

SCHÄFER A, VAGEDES J: How accurate is pulse rate variability as an estimate of heart rate variability? A review on studies comparing photoplethysmographic technology with an electrocardiogram. Int J Cardiol 166: 15-29, 2013. https://doi.org/10.1016/j.ijcard.2012.03.119

SOUKUP L, HRUSKOVA J, JURAK P, HALAMEK J, ZAVODNA E, VISCOR I, MATEJKOVA M, VONDRA V: Comparison of noninvasive pulse transit time determined from Doppler aortic flow and multichannel bioimpedance plethysmography. Med Biol Eng Comput 57: 1151-1158, 2019. https://doi.org/10.1007/s11517018-01948-X

STRAIN WD, PALDÁNIUS PM: Diabetes, cardiovascular disease and the microcirculation. Cardiovasc Diabetol 17: 57, 2018. https://doi.org/10.1186/s12933-018-0703-2 
SVACINOVA J, JAVORKA M, NOVAKOVA Z, ZAVODNA E, CZIPPELOVA B, HONZIKOVA N: Development of causal interactions between systolic blood pressure and inter-beat intervals in adolescents. Physiol Res 64: 821-829, 2015. https://doi.org/10.33549/physiolres.933047

TRIPKOVIC L, HART K H, FROST GS, LODGE JK: Interindividual and intraindividual variation in pulse wave velocity measurements in a male population. Blood Press Monit 19: 233-241, 2014. https://doi.org/10.1097/MBP.0000000000000052

VERROTTI A, PREZIOSO G, SCATTONI R, CHIARELLI F: Autonomic neuropathy in diabetes mellitus. Front Endocrinol (Lausanne) 5: 205, 2014. https://doi.org/10.3389/fendo.2014.00205

VLACHOPOULOS C, AZNAOURIDIS K, STEFANADIS C: Prediction of cardiovascular events and all-cause mortality with arterial stiffness. a systematic review and meta-analysis. J Am Coll Cardiol 55: 1318-1327, 2010. https://doi.org/10.1016/j.jacc.2009.10.061

VONDRA V, JURAK P, VISCOR I, HALAMEK J, LEINVEBER P, MATEJKOVA M, SOUKUP L: A multichannel bioimpedance monitor for full-body blood flow monitoring. Biomed Tech (Berl) 61: 107-118, 2016. https://doi.org/10.1515/bmt-2014-0108

WANG R, JIA W, MAO Z-H, SCLABASSI R J, SUN M: Cuff-free blood pressure estimation using pulse transit time and heart rate. Int Conf Signal Process Proc 2014: 115-118, 2014. https://doi.org/10.1109/ICOSP.2014.7014980

WANG S, RANDALL DC, KNAPP CF, PATWARDHAN AR, NELSON KR, KAROUNOS DG, EVANS JM: Blood pressure regulation in diabetic patients with and without peripheral neuropathy. Am J Physiol Regul Integr Comp Physiol 302: R541-R550, 2012. https://doi.org/10.1152/ajpregu.00174.2011

WELTMAN G, SULLIVAN G, BREDON D: The continuous measurement of arterial pulse wave velocity. Med Electron Biol Eng 2: 145-154, 1964. https://doi.org/10.1007/BF02484213

WEN W, LUO R, TANG X, TANG L, HUANG H X, WEN X, HU S, PENG B: Age-related progression of arterial stiffness and its elevated positive association with blood pressure in healthy people. Atherosclerosis 238: 147-152, 2015. https://doi.org/10.1016/j.atherosclerosis.2014.10.089

ZHANG M, BAI Y, YE P, LUO L, XIAO W, WU H, LIU D: Type 2 diabetes is associated with increased pulse wave velocity measured at different sites of the arterial system but not augmentation index in a Chinese population. Clin Cardiol 34: 622-627, 2011. https://doi.org/10.1002/clc.20956 